\title{
Combined Oral Contraceptive Use at the University of Port Harcourt Teaching Hospital, Port Harcourt, Southern Nigeria: A-20 Year Review
}

\author{
John Dimkpa Ojule*, Emmanuel Okwudili Oranu \\ Department of Obstetrics and Gynaecology, University of Port Harcourt Teaching Hospital, Port Harcourt, Nigeria \\ Email: *ojulejohn@yahoo.com
}

How to cite this paper: Ojule, J.D. and Oranu, E.O. (2017) Combined Oral Contraceptive Use at the University of Port Harcourt Teaching Hospital, Port Harcourt, Southern Nigeria: A-20 Year Review. Journal of Biosciences and Medicines, 5, 7-17.

https://doi.org/10.4236/jbm.2017.56002

Received: May 16, 2017

Accepted: June 24, 2017

Published: June 27, 2017

Copyright $\odot 2017$ by authors and Scientific Research Publishing Inc. This work is licensed under the Creative Commons Attribution International License (CC BY 4.0).

http://creativecommons.org/licenses/by/4.0/

\begin{abstract}
Background: While the combined oral contraceptive pill (COCP) is one of the most commonly used methods of birth control especially in the developed countries, robust and current information on the pill use in developing countries including Nigeria is at best lacking. Objectives: The study was conducted to determine the prevalence rate, efficacy and side effects of COCP at the University of Port Harcourt Teaching Hospital (UPTH), Port Harcourt, Southern Nigeria. Methods: It was a retrospective analysis of all clients who used the COCP between $1^{\text {st }}$ January 1997 and $31^{\text {st }}$ December, 2016, at the family planning clinic of UPTH Port Harcourt. Data on sociodemographic profile, side effects and source of information were extracted from the clients' case notes coded and fed into Excel spread sheet and analysed. Results: Of the 8310 new acceptors of modern contraceptive methods in UPTH, 399 clients used the COCP, giving a prevalence rate of $4.8 \%$. The mean age of the acceptors was $26.42 \pm 4.27$ years while the mean parity was $1.90 \pm 0.36$. Menstrual disruption was the most common complications with 78 episodes constituting $47.0 \%$ of all the complications. One unintended pregnancy occurred during the period of observation, giving a Pearl index of 0.01 . Conclusion: The study showed that although COCP is very effective, readily available, safe and reliable method of fertility control, the acceptance rate is very low and the patronage rapidly declining and may therefore go into extinction as a family planning method in Port Harcourt, Southern, Nigeria.
\end{abstract}

\section{Keywords}

Combined Oral Contraceptive Pill, Nigeria, Port Harcourt, Twenty Years 


\section{Introduction}

The combined oral contraceptive pills (COCP), no doubt, are one of the most commonly used methods of family planning worldwide [1]. They are the first contraceptive method to provide sexual freedom of choice for women through reliable, personal and private control of fertility [2], and represent the most studied class of drug since its introduction in 1960 [3].

Their very high effectiveness, safety, reliability, reversibility, widespread availability and ease of administration make them attractive options for contracepting women [3] [4], and act primarily by inhibition of ovulation, thickening of cervical mucus and induction of endometrial atrophy [5] [6] [7].

They contain an estrogen (ethinyl estradiol, estradiol valerate or mestranol) and a progestogen (levonorgestrel, norethisterone, gestodene, desogestrel, drospirenone, nomegestrel or cyproterone). Of the estrogens, ethinyl estradiol, a derivative of 17 beta estradiol had been the most predominant estrogen in COCP due to its high oral bioavailability compared to estradiol [8]. However, more recently, estradiol has been combined with a synthetic esther to form estradiol valerate in an effort to improve its oral bioavailabilty and its half life [9]. Estradiol valerate has much better impact on hemostasis, carbohydrate and lipid metabolism than ethinyl estradiol [10], and therefore increasingly replacing ethinyl estradiol in COCP [8].

Some of the drawbacks of the estrogen component of the COCP are nausea, bloating, breast tenderness and most importantly thrombo-embolism reportedly worse with ethiny estradiol dose greater than $50 \mu \mathrm{g}$ [8]. In order to reduce these adverse effects, scientists have continued to lower the estrogen dose in COCP resulting in better safety profile while maintaining the efficacy [8] [11].

Based on the strength of the estrogen component, there are three categories of COCP: high dose (containing $>50 \mu \mathrm{g}$ of estradiol), medium dose (containing 50 $\mu \mathrm{g}$ ) and low dose (containing $<50 \mu \mathrm{g}$ ) [12]. The standard dose of ethinyl estradiol in later formulations was reduced to $\leq 35 \mu \mathrm{g}$ to minimise the untoward effects [13].

Conversely, the progestogen component of the earlier pills included norethisterone or levonorgestrel which has some androgen and glucocorticoid effects. More recently, newer progestogens-gestodene, desogestrel, and most recently drospirenone which has greater specificity for progestogen receptors than the older progestogens have been introduced and these have little or no androgenic properties [8].

Although various formulations of COCP exists, they are mostly available in a 28-day packs with 21 days active and 7 days inactive pills (placebo) to mimic the 28 days menstrual cycle. There is also the 24 active and 4 inactive pills (24/4 regime) which reduces the chance of breakthrough ovulation [14].

They can also be packaged as monophasic, biphasic, triphasic or quadriphasic formulations depending on the variation in the concentrations of the estrogen and progestogen in a pack [12].

The COCP also have numerous non-contraceptive uses. They can be used in 
the treatment of menorrhagia, dysfunctional uterine bleeding, dysmenorrhea and also used in amelioration of course of rheumatoid arthritis [15] [16].

They also protect women against pelvic inflammatory disease, endometriosis, ovarian and endometrial cancers [12].

They are contraindicated in women with Diabetes mellitus, severe hypertension and women who are breastfeeding and those older than 35 years [8]. Also women with previous history of thrombo-embolism, cardiovascular and chronic liver disease are not to be given COCP.

At the University of Port Harcourt Teaching Hospital (UPTH) like most other centres across Nigeria, the COCP available at the Family planning clinic since its inception over 3 decades ago are only the low dose monophasic pills. This is because it is only the federal government of Nigeria through the federal ministry of health that provides contraceptive commodities to all government facilities offering family planning services at no cost to the end user. It is probable that the multiphasic preparations may be more expensive than the monophasic pills. Additionally, no studies to date have demonstrated higher contraceptive efficacy of the multiphasic drugs over the monophasic formulations. The available monophasic preparations in our centre include Locon-F (containing $0.1 \mathrm{mg}$ levonorgestrel and $0.02 \mathrm{mg}$ ethinyl estradiol), Lo-femina ( $0.3 \mathrm{mg}$ norgestrel and $0.03 \mathrm{mg}$ ethiynl estradiol) and microgynon $(0.15 \mathrm{mg}$ levonorgestrel and $0.03 \mathrm{mg}$ ethinyl estradiol).

The only study on COCP in our centre was the one done on women using this contraceptive commodity between 1997 and 2006 [17]. Periodic and comprehensive review of COCP use is essential to provide updates on all aspects the pill use in Port Harcourt, capital city of the oil rich Rivers state of Nigeria.

Evaluating the COCP use over a-20 year period will also enable us determine more accurately the level and trend of utilization of this contraceptive pill in our environment and compare same with the uptake rate elsewhere using a comprehensive data base. It will also enable us determine and document more reliably the effectiveness and safety profile of this fertility control method, thus providing more robust information on the pill use in Port Harcourt.

The study was therefore conducted to re-evaluate the pill use in Port Harcourt and determine the acceptance rate, efficacy, safety and complications of combined oral contraceptive at the University of Port Harcourt Teaching Hospital, Port Harcourt, Southern Nigeria.

\section{Materials and Methods}

The family planning clinic of the UPTH, Port Harcourt, is located within the department of Obstetrics and Gynaecology complex of the hospital. The clinic runs from Monday to Friday, 8 am to $4 \mathrm{pm}$.

The clients are sourced from the general out-patient clinic, post natal clinic, and immunization centre of the hospital and from outside the hospital including neighbouring towns and states.

At presentation, the clients are counselled by trained family planning nurses 
and physicians and guided to make informed choice based on their need and available contraceptive methods suitable for them. A detailed health history is taken and clinical examination performed. A urinalysis and pregnancy test (for those not menstruating) are then done.

COCP are usually given within the first 5 days of menstruation and as soon as possible after abortion or miscarriage. Follow up visits, in the absence of complications are usually 4 weeks after and subsequently every 3 months. At each follow up visit, the clients' blood pressure and weight are recorded. All complaints volunteered are documented and complications managed appropriately. Clients are considered lost to follow up when they did not report for 2 or more consecutive scheduled visits.

Clients who are pregnant, diabetic, severely hypertensive or have chronic liver disease, and history of thrombo-embolism are usually counselled against using combined oral contraceptive pills.

The case notes of all new clients who accepted the combined COCP for contraception between $1^{\text {st }}$ January 1997 and $31^{\text {st }}$ December 2016 were retrieved and studied.

Data extracted from their files included clients' age, marital status, parity, religion, level of education, side effects, source of information, method change and reasons for discontinuation. The data were entered into excel spread sheet and analysed using frequency counts and percentages.

\section{Results}

Of the 8310 new acceptors of modern contraceptives during the study period, 399 clients accepted and used the COCP, giving a prevalence rate of $4.8 \%$. Those who chose barrier methods were excluded because most of them do not return for follow up visits and therefore not known whether or not they actually used the method.

The mean age of the patients was $26.42 \pm 4.27$ years with a range of $14-41$ years. There were 25 teenagers constituting $6.8 \%$ while those aged 35 years and above were 22 clients, representing 5.5\%. The modal age range was 25 - 29 years constituting $39.6 \%$ of the clients as shown in Table 1.

The parity range was $0-6$ with a mean parity of $1.90 \pm 0.36$. There were 85 nulliparous women representing $21.3 \%$ of the clients while grandmultiparous women were 23 constituting $5.7 \%$.

Majority, (61.6\%) were single while 153 (38.4\%) clients were married. Similarly, most (95.0\%) were Christians while only 20 (5.0\%) clients were moslems.

Up to $99.5 \%$ of the clients had at least a primary education, with 229 (57.4\%) having tertiary education. Only $2(0.5 \%)$ did not have a formal education.

Table 2 shows the yearly acceptance of combined oral contraceptive pill. Fifty-seven (14.3\%) accepted the COCP in 1997. The acceptance gradually dropped over the years to 14 (3.5\%) clients in the year 2006. During the first 10 years (1997-2006), a total of 360 clients accepted the COCP representing 90.2\% of the acceptors over the entire study period. The second decade of the study 
Table 1. Sociodemographic characteristics of acceptors.

\begin{tabular}{|c|c|c|}
\hline Variable & No. & Percentage \\
\hline \multicolumn{3}{|l|}{ Age (years) } \\
\hline$\leq 19$ & 25 & $6.3 \%$ \\
\hline $20-24$ & 83 & $20.8 \%$ \\
\hline $25-29$ & 158 & $39.6 \%$ \\
\hline $30-34$ & 111 & $27.8 \%$ \\
\hline$\geq 35$ & 22 & $5.5 \%$ \\
\hline \multicolumn{3}{|l|}{ Marital status } \\
\hline Single & 246 & $61.6 \%$ \\
\hline Married & 153 & $38.4 \%$ \\
\hline \multicolumn{3}{|l|}{ Parity } \\
\hline 0 & 85 & $21.3 \%$ \\
\hline $1-4$ & 291 & $73.0 \%$ \\
\hline$\geq 5$ & 23 & $5.7 \%$ \\
\hline \multicolumn{3}{|l|}{ Educational level } \\
\hline No formal education & 2 & $0.5 \%$ \\
\hline Primary & 20 & $5.0 \%$ \\
\hline Secondary & 148 & $37.1 \%$ \\
\hline Tertiary & 229 & $57.4 \%$ \\
\hline \multicolumn{3}{|l|}{ Religion } \\
\hline Moslem & 20 & $5.0 \%$ \\
\hline Christianity & 379 & $95 \%$ \\
\hline Total & 399 & $100.0 \%$ \\
\hline
\end{tabular}

Table 2. Yearly acceptance of combined oral contraceptive pill.

\begin{tabular}{cccccc}
\hline Year & Number & Percentage & Year & Number & Percentage \\
\hline 1997 & 57 & $14.3 \%$ & 2007 & 7 & $1.7 \%$ \\
1998 & 55 & $13.7 \%$ & 2008 & 18 & $4.5 \%$ \\
1999 & 41 & $10.3 \%$ & 2009 & 3 & $0.8 \%$ \\
2000 & 47 & $11.8 \%$ & 2010 & 5 & $1.2 \%$ \\
2001 & 45 & $11.3 \%$ & 2011 & 0 & $0.02 \%$ \\
2002 & 27 & $6.7 \%$ & 2012 & 1 & $0.3 \%$ \\
2003 & 25 & $6.3 \%$ & 2013 & 4 & $1.0 \%$ \\
2004 & 24 & $6.0 \%$ & 2014 & 0 & $0.0 \%$ \\
2005 & 25 & $6.3 \%$ & 2015 & 1 & $0.3 \%$ \\
2006 & 14 & $3.5 \%$ & 2016 & 0 & $0.0 \%$ \\
Total & 360 & $92.2 \%$ & Total & 39 & $9.8 \%$ \\
Grand total & 399 & $100 \%$ & & & \\
\hline
\end{tabular}

(2007-2016) showed further dramatic decline in COCP acceptance ranging from $7(1.7 \%)$ clients in 2007 to zero (0\%) in 2016 at the end of the observation period representing $9.8 \%$ acceptance over the 20 years period.

The distribution of the source of information on family planning is as shown on Table 3. 
One hundred and forty-four (36.1\%) clients had the information from the mass media, while 80 (20.0\%) had about contraception from friends and relatives.

Table 4 shows the frequency of side effects experienced by acceptors of the COCP. Menstrual complications were the most common with 78 episodes constituting $47.0 \%$ of all the complications. Of these, $32.0 \%$ was secondary amenorrhea, $6.6 \%$ each was hypomenorrhea and intermenstrual bleeding while the least common was menorrhagia accounting for $1.8 \%$. The most prevalent non-menstrual side effect was weight gain which occurred in 61 (37\%) clients, while the least common were breast pain, nausea and vaginal discharge accounting for $0.6 \%$ each.

There was one case of unintended pregnancy which occurred in a 25 year old nulliparous client after 2 years of COCP use, giving a Pearl Index of 0.01. She requested for a termination of pregnancy which was not granted because of the restrictive abortion laws in Nigeria.

Forty-eight (12.0\%) discontinued COCP use for reasons which were not stated. Out of these, 20 (41.7\%) changed to injectable contraceptives, 9 (18.8\%) each changed to progestogen only injectable contraceptives and implants while 2 $(0.5 \%)$ changed to Intra uterine device.

Table 3. Source of information on family planning.

\begin{tabular}{ccc}
\hline Source & No. & Percentage \\
\hline Mass media & 144 & $36.1 \%$ \\
Health clinics & 86 & $21.6 \%$ \\
Friends/relatives & 80 & $20.0 \%$ \\
Medical Outreaches/ Health personnel & 89 & $22.3 \%$ \\
Total & 399 & $100.0 \%$ \\
\hline
\end{tabular}

Table 4. Frequency of complications.

\begin{tabular}{ccc}
\hline Side effect & frequency & Percentage \\
\hline Menstrual & & \\
Secondary amenorrhea & 53 & $32.0 \%$ \\
Hypomenorrhea & 11 & $6.6 \%$ \\
Intermenstrual bleeding & 11 & $6.6 \%$ \\
Menorrhagia & 3 & $1.8 \%$ \\
Non-menstrual & & \\
Weight gain & 61 & $36.8 \%$ \\
Hypertension & 8 & $4.8 \%$ \\
Headache & 8 & $4.8 \%$ \\
Dizziness & 4 & $2.4 \%$ \\
Chest pain & 2 & $1.2 \%$ \\
Skin rashes & 2 & $1.2 \%$ \\
Breast pain & 1 & $0.6 \%$ \\
Nausea & 1 & $0.6 \%$ \\
Vaginal discharge & 1 & $0.6 \%$ \\
Total & 166 episodes & $100.0 \%$ \\
\hline & &
\end{tabular}




\section{Discussion}

The combined oral contraceptive is an effective family planning method which also has numerous non contraceptive benefits and uses [8]. By regulating hormonal fluctuations, COCPs improves or relieves some disturbing physical symptoms of menstruation such as painful menstruation, and breast discomforts [8]. COCP also reduces the duration and heaviness of menstrual blood loss and as such can be used in treatment of menorrhagia. They also ameliorate the symptoms of endometriosis [18], and offers protection against some gynaecological malignancies [19] [20] amongst other benefits.

Their very high efficacy, safety, availability, affordability and numerous noncontraceptive benefits of COCP are the major reasons why the pills are reportedly used by over 100 million women worldwide especially in the developed countries [8] [21] [22].

However, despite all these benefits, the COCP are not that popular among women who want to space or limit pregnancies in the developing countries including Nigeria [23]. It is therefore not surprising that the uptake rate of COCP in this study is $4.8 \%$, down from the $8.7 \%$ prevalence rate reported in a previous study in Port Harcourt [19]. Quite disturbing is the very sharp decline to $9.8 \%$ in COCP patronage in the last 10 years of the study, abysmally dropping to $0 \%$ in the last year of observation. The reasons for the low and subsequent declining patronage may be due to the health concerns and false rumours about health problems associated with COCP, annoying side effects and negative perception of increased risk of infertility attributed to pill use [24] [25] [26]. Additionally, the introduction and increasing acceptance of the implant contraceptives in UPTH which is also highly effective, long acting, easily reversible, and requiring much less frequent hospital visit [27], may have contributed to the very low COCP prevalence rate. Implanon acceptance rapidly increased from $1.8 \%$ in 2006 at its introduction to $53 \%$ in 2008 [27].

Majority of the clients in this study were in the age range of 15 - 29 years consistent with findings of other researchers [19]. This is not surprising because it is the age group mostly at risk of unintended pregnancies and unsafe abortions following unprotected sex [28] [29], in keeping with findings elsewhere [30] [31]. Similarly, majority of the pill users were single ladies, further compounding the risk of unplanned pregnancies and criminal pregnancy terminations. This trend is similar to findings by other researchers in Nigeria and other parts of the world [19] [30] [31].

Also, majority of the acceptors were educated up to the tertiary level. This is also not surprising because the level of education affects family planning awareness and uptake and effective and consistent COCP use may be related to higher education [19].

The least users of the COCP in this study were the grandmultiparous women. Again this is not surprising in our environment because most women of high parity have many domestic concerns which may interfere with the compliance with COCP and therefore may opt for methods which are not client dependent. 
Additionally, these grandmultiparous women would probably have been above 35 years which is the age above which COCP use may not be very suitable for, because of increased risk of cardiovascular diseases and thrombo-embolism [19].

The few women 35 years and above who used COCP in this study would have been appropriately counselled to choose other forms of contraceptives suitable for them.

Menstrual complications were the most common side effects reported by users of COCP and amongst these, secondary amenorrhea were the commonest. These menstrual disruptions have been attributed to the endogenous ovarian steroid secretions and endometrial angiogenesis [32] [33]:

Weight gain occurred in $36.8 \%$ of the clients in this study, similar to result of earlier study [19].

Although this may be due to the anabolic property of the steroid and its associated increase in induction of appetite [34], normal age related increase in weight may also have contributed.

Only one accidental pregnancy occurred during the 20 years observation period, giving a Pearl index of 0.01. Findings revealed that the 25 year old nulliparous lady who conceived while on COCP was not compliant with the daily intake of the pills. Appropriate and correct pill use have earlier been reported to require high level of motivation by the user. This motivation is extremely important because the efficacy of the pill depends largely on compliance with the daily intake regime of COCP.

The retrospective nature of this study and its inherent problems including incomplete records in some clients' case notes are the major limitations of this study. A prospective study with a questionnaire section may explain reasons why women in Port Harcourt will prefer other contraceptive methods to the COCP in our centre. It will also help in correcting the documentation lapses.

\section{Conclusion}

Combined oral contraceptive is very effective, safe and reliable method of fertility control but with very low and declining acceptance, in Port Harcourt, southern Nigeria. This is probably due to the availability and increasing acceptability of implants with even higher contraceptive efficacy, much less return visits and not requiring daily administration unlike the COCP. If this trend continuous and which is very likely, the COCP may go into extinction at the UPTH family planning clinic, just like the combined injectable contraceptive (CIC) did few years back [35]. Considering also the numerous non-contraceptive benefits of the COCP, all the various levels of government in Nigeria should make deliberate efforts to improve the uptake of this contraceptive among our women.

\section{Acknowledgements}

We wish to express our gratitude the family planning nurse practitioners for their assistance in sorting out the clients' case files and other staff of the family planning unit for their support and understanding throughout the period of study. 


\section{References}

[1] Gallo, M.F., Grimmes, D.A., Schulz, K.F. and Helmershorst, F.M. (2004) Combination Estrogen-Progestin Contraceptives and Body Weight: Systematic Review of Randomised Control Trials. Obstetrics \& Gynecology, 103, 359-373. https://doi.org/10.1097/01.AOG.0000107298.29343.6a

[2] Fraser, I.S. (2000) Forty Years of Combined Oral Contraception: The Evolution of a Revolution. The Medical Journal of Australia, 173, 541-544.

[3] Finger, W.R. (1996) Oral Contraceptives Are Very Safe, Very Effective. Network, 16, 4-5.

[4] Russell, R. and Kingsland, C. (2008) The Risks and Benefits of Combined Oral Contraceptive Pill. The Journal of the Royal College of Physicians of Edinburgh, 38, 224-227.

[5] Emuveyan, E.E. (2005) Advances in Contraception. In: Kwawukume, E.Y. and Emuveyan, E.E., Eds., Comprehensive Gynaecology in the Tropics, Graphic packaging Ltd., Accra, 233-246.

[6] Kripke, C. (2006) Cyclic vs Continuous or Extended Cycle Combined Contraceptives. American Family Physician, 73, 804.

[7] Edmonds, K. and Gebbie, A.E. (2006) Fertility Control. In: Monga, A., Ed., Gynaecology by Ten Teachers, 18th Edition, Book Power Publishing Company, London, 59-75.

[8] Stewart, M. and Black, K. (2015) Choosing a Combined Oral Contraceptive Pill. Australian Prescriber, 38, 6-11. https://doi.org/10.18773/austprescr.2015.002

[9] Fraser, I.S., Jensen, J., Schaefers, M., Mellinger, U., Parke, S. and Serrani, M. (2012) Normalisation of Blood Loss in Women with Heavy Menstrual Bleeding Treated with Oral Containing Estradiol Valerate/Dienogest. Contraception, 86, 96-101. https://doi.org/10.1016/j.contraception.2011.11.011

[10] Fruzzetti, F., Tremollieres, F. and Bitzer, J. (2012) An Overview of the Development of Combined Oral Contraceptives Containing Estradiol: Focus on Estradiol Valerate/Dienogest. Gynecological Endocrinology, 28, 400-408.

https://doi.org/10.3109/09513590.2012.662547

[11] Iklaki, C.U., Inaku, J.E., Ekabua, J.E., Odusolu, P.O. and Njoku, C.O. (2012) Use of Combined Oral Contraceptive Pill among Teenage Girls in Calabar, Nigeria. Open Access Journal of Contraception, 3, 31-35.

[12] Michelle, M.D., Roland, T. and Burkman, M.D. (2003) Contraception and Family Planning. In: Decherny, A.H. and Laurent, N., Eds., Current Obstetrics and Gynaecologic Diagnosis and Treatment, Lang Medical Books/McGraw-Hill Companies, Inc., New York, 631-650.

[13] Mansour, D., Inki, P. and Gemzell-Danielsson, K. (2010) Efficacy of Contraceptive Methods. A Review of the Literature. The European Journal of Contraception and Reproductive Health Care, 15, 4-16. https://doi.org/10.3109/13625180903427675

[14] Klippin, C., Duijkens, T., Trummer, D. and Marr, J. (2008) Suppression of Ovarian Activity with Drospirenone Containing Oral Contraceptive in a 24/4 Regime. Contraception, 78, 16-25. https://doi.org/10.1016/j.contraception.2008.02.019

[15] Curtis, K.M., Chrisman, C.E. and Peterson, A.B. (2002) WHO Programme for Mapping Best Practices in Reproductive Health. Contraception for Women in Selected Circumstances. Obstetrics \& Gynecology, 99, 1100-1112.

[16] Hatcher, R.A., Trussel, J., Stewart, F., et al. (2004) Contraceptive Technology. 18th Edition, Adent Media, New York, 236, 374, 327. 
[17] Enyindah, C.E. and Nonye-Enyindah, E. (2011) Contraception with Combined Oral Contraceptive in Port Harcourt, Nigeria. PMJ, 6, 81-88.

[18] World Health Organisation (2011) Department of Reproductive Health and Research. Family Planning: A Global Handbook for Providers: Evidence-Based Guidance Developed through Worldwide Collaboration, Geneva Switzerland. WHO centre for Communications Program, 1-10.

[19] Havrilesky, L.J., Moorman, P.G., et al. (2013) Oral Contraceptive Pills as Primary Prevention for Ovarian Cancer: A Systematic Review and Meta-Analysis. Obstetrics \& Gynecology, 122, 30-142.

[20] Shulman, L.P. (2011) The State of Hormonal Contraception Today: Benefits and Risks of Hormonal Contraceptives: Combined Estrogen and Progestin Contraceptives. American Journal of Obstetrics \& Gynecology, 205, S9-S13. https://doi.org/10.1016/j.ajog.2011.06.057

[21] Taylor, T., Keyse, L. and Bryant, A. (2005/2006) Contraception and Sexual Health. Office for National Statistics, London.

[22] Mosher, W.D., Martinez, A.M., et al. (2004) Use of Contraception and Use of Family Planning Services in the United States: 1982-2002. Advanced Data, 350, 1-36.

[23] Ojule, J.D. and Oranu, E.O. (2017) Birth Control Pills Profile of Acceptors at the University of Port Harcourt Teaching Hospital, Port Harcourt Nigeria. British Journal of Medicine and Medical Research, 20, 1-7. https://doi.org/10.9734/BJMMR/2017/32069

[24] Grubb, G.S. (1987) Women Perception of the Safety of the Pill: A Survey of Eight Countries. Journal of Biosocial Science, 19, 313-321. https://doi.org/10.1017/S0021932000016965

[25] Khan, M.A. (2001) Side Effects and Oral Contraceptive Discontinuation in Rural Bangladesh. Contraception, 64, 161-167. https://doi.org/10.1016/S0010-7824(01)00238-4

[26] Peru, C.M.D. (1991) Demographic and Health Survey 1991-1992. Macro International Inc., Demographic and Health Survey, Dominican Republic.

[27] Ojule, J.D., Oranu, E.O. and Enyindah, C.E. (2012) Experience with Implanon in Southern Nigeria. JMMS, 3, 710-714.

[28] Adewole, I.F., Oye-Adeniran, B.A., Iwere, N., et al. (2002) Contraceptive Usage among Abortion Seekers in Nigeria. West African Journal of Medicine, 21, 112-114.

[29] Wu, J., Wang, L., Rauyajin, O. and Good, S. (2002) Contraceptive Use Behaviour among Never Married Young Women Who Are Seeking Pregnancy Termination in Beijing. Chinese Medical Journal, 115, 851-855.

[30] Savabi-Esfahany, M., Fadaei, S. and Yousefy, A. (2006) Use of Combined Oral Contraceptives in Isfahan, Islamic Republic of Iran. Eastern Mediterranean Health Journal, 12, 417-422.

[31] Oye-Adeniran, B.A., Adewole, I.F., Odeyemi, K.A., Ekanem, E.E. and Umoh, A.V. (2005) Contraceptive Prevalence among Young Women in Nigeria. Journal of $O b$ stetrics and Gynaecology, 25, 182-185. https://doi.org/10.1080/01443610500041156

[32] Datey, S., Gaur, L.N. and Saxena, B.N. (1995) Vaginal Bleeding Patterns of Women Using Different Contraceptive Methods (Implants, Injectables, IUDs, Oral Pills): An Indian Experience. An ICMR Task Force Study. Contraception, 51, 155-165. https://doi.org/10.1016/0010-7824(95)00012-Y

[33] Chigbu, B., Onwere, S., Aluka, C., Kamanu, C., Okoro, O. and Feyi-Waboso, P. (2010) Contraceptive Choices of Women in Rural South-Eastern Nigeria. Nigerian Journal of Clinical Practice, 13, 195-199. 
[34] Rosenberg, M. (1998) Weight Change with Oral Contraceptive Use and during the Menstrual Cycle. Results of Daily Measurements. Contraception, 58, 345-349. https://doi.org/10.1016/S0010-7824(98)00127-9

[35] Ojule, J.D. and Oranu, E.O. (2017) Experience with Combined Injectable Contraceptive (Norigynon) in Port Harcourt. British Journal of Medicine and Medical Research, 19, 1-6. https://doi.org/10.9734/BJMMR/2017/29727

Submit or recommend next manuscript to SCIRP and we will provide best service for you:

Accepting pre-submission inquiries through Email, Facebook, LinkedIn, Twitter, etc. A wide selection of journals (inclusive of 9 subjects, more than 200 journals)

Providing 24-hour high-quality service

User-friendly online submission system

Fair and swift peer-review system

Efficient typesetting and proofreading procedure

Display of the result of downloads and visits, as well as the number of cited articles

Maximum dissemination of your research work

Submit your manuscript at: http://papersubmission.scirp.org/

Or contact jbm@scirp.org 